\title{
Endovascular management of middle cerebral artery aneurysms (single-center case series study)
}

\author{
Mostafa Mohamed Mostafa Elian', Ahmed Sayed Ibrahim Issa ${ }^{1 *}$ (D), Mohamed Ahmed Ibrahim', \\ Osama Abd El Wadood Khalil ${ }^{1}$ and Farouk Hassan Youssef ${ }^{2}$
}

\begin{abstract}
Background: Middle cerebral artery (MCA) aneurysms were usually subjected to treatment by surgery, while endovascular treatment (EVT) was performed only in chosen patients. We assessed the efficacy, safety, and durability in addition to the clinical outcome of EVT when it is regarded as the first-line treatment modality for MCA aneurysms.

Results: We recruited 30 patients with MCA aneurysms who underwent definitive management from July 2017 to July 2018. All those patients were treated endovascularly; 22 patients (73.3\%) presented with subarachnoid hemorrhage, and 8 patients (26.7\%) had different presentations, including isolated headaches and seizures. EVT was performed for all patients and required the use of a balloon, stent, or double catheter techniques in 13 cases and flow diverter stents alone in two cases. Clinical outcome was assessed by the modified Rankin Scale (mRS) at 3 months. Angiographic follow-up was done by a conventional angiography at 6 months and after 1 year. EVT was efficiently conducted, leading to an outstanding accomplishment (mRS $=1-2$ ) in 29 patients. However, one patient had a thromboembolic complication, followed by death after severe chest infection that was not related to the procedure. Immediate anatomical results included complete aneurysmal occlusion with the establishment of normal cerebral circulation. Angiographic follow-up revealed 24 unchanged occlusions and 5 cases with recanalization that required further treatment.

Conclusion: EVT of MCA aneurysms is a viable treatment option with positive outcomes in most cases. Nevertheless, the employment of long-term imaging follow-up is compulsory for validating such early results, often with respect to anatomical and functional stability.
\end{abstract}

Keywords: Aneurysm, Endovascular treatment, Middle cerebral artery, Remodeling techniques

\section{Background}

MCA aneurysms represents $14.0-34.0 \%$ of all cerebral aneurysms [1] and represents the third most prevalent site for ruptured intracranial aneurysms, comprising 18-22\% [2]. Conventionally, MCA aneurysms have been known to experience difficulty in endovascular treatment because of different hazards, including undesirable dome-to-neck ratio as well as incorporating

\footnotetext{
* Correspondence: Ahmed.Issa@mu.edu.eg

'Radiology Department, Faculty of Medicine, Minia University, Minia, Egypt

Full list of author information is available at the end of the article
}

neighboring arterial branches at the aneurysmal base [2-4]. As a result, the MCA represents a rare location for aneurysms, where several institutions even now recommend surgical clipping over endovascular treatment [5]. After evolution of endovascular era in the past decade, growing attention has been dedicated to endovascular treatment for MCA aneurysms [6].

For endovascular treatment, several reports have manifested the feasibility as well as efficacy for such treatment. However, they stay quite under-represented in the literature, and their findings differ greatly with different ranges of feasibility from 81.7 to $95.2 \%$ [2, 3, 7-10]. 
Successful outcome is defined radiographically as complete or near-complete occlusion of aneurysm, ranging between 82.4 and $97 \%$, while significant recanalization needing retreatment ranging between 6.1 and $20 \%[2,3,6-10]$.

In 2011, a systematic review was intended to evaluate 1076 MCA aneurysms, which were subjected to endovascular treatment, resulting in a feasibility rate of $95.2 \%$ with complete or near-complete occlusion of $82.4 \%$, while incomplete occlusion reached $12.7 \%$ [10]. It was identified that upon long-term follow-up, treated aneurysms with stability or progress to more complete occlusion were $81 \%$, treated aneurysms with minor recurrence without need to retreatment were $9.3 \%$, while treated aneurysms featuring significant recurrence with a need to retreatment were $9.6 \%$ [10].

Management of middle cerebral artery aneurysms has been therefore challenged and perplexed in the presence of such changes in aneurysm practice [11-14].

In Egypt, the practice outcome needs evaluation especially at low-volume centers. The purpose to ensure and measure the feasibility, effectiveness, safety, and endovascular management results in terms of clinical outcomes, procedural mortality, morbidity, and shortand long-term angiographic outcomes in consecutive 30 cases with MCA aneurysms when the endovascular approach is the first-line treatment modality.

\section{Methods}

We analyzed the results of 30 cases of MCA aneurysms who were subjected to treatment from July 2017 to July 2018 in a consecutive manner. All patients or their firstdegree relatives (if not fully conscious) signed a written approval for participation.

Certain variables were collected, including demographic data of the patients, presentation mode (ruptured or unruptured), and characteristics of the aneurysms in addition to preoperative as well as postoperative functional status with respect to modified Rankin scale (MRS) grading systems. The radiographic parameters involved aneurysms number, size, location, neck size, and whether incorporation of an arterial vessel was realized into the neck or the aneurysm dome.

We included all patients aged from 18 to 80 years with ruptured or unruptured MCA aneurysms either presented on their preference or upon combined decision with the neurology or neurosurgery department.

We excluded other patients out of the age range and those with impaired renal or coagulation profiles; also, patients with significant impairment (GCS $<8$ or mRS 4.,5) were excluded.

The location of aneurysm was divided into different categories, including M1 segment without a bifurcation,
MCA bifurcation, or M2 distal to the bifurcation. Variables of the procedure depend on the successful accomplishment of intervention as well as adjuvant device utilization like balloons or stents.

Cases were evaluated by MDCT angiography after initial screening by non-enhanced MDCT for further vascular analysis and as a pre-procedural analysis of the apparent aneurysmal features (Toshiba Aquilion 64slice CT system).

The instant radiographic result was designated utilizing the Raymond grading scale [13], and complete (Raymond 1) or near-complete occlusion (Raymond 2) was identified. A complication by definition was an event that happened, requiring supplementary intervention during or recent post-procedure or those that led to a perpetual neurological imbalance. Morbidity, by definition, was a perpetual negative influence on the life quality of a patient and its direct relation to the procedure.

Radiographic data based on follow-up were obtained by using catheter angiography.

Comparison between Raymond classification based on follow-up and immediate Raymond classification was accomplished and then utilized for describing the progression of the treated aneurysm over time.

Modified Rankin score was used to assess short-term clinical results.

\section{Endovascular procedure}

Endovascular procedures were conducted by means of Monoplane X-ray angiography (Philips Allura clarity catheter, with capability of subtraction, road mapping, high frame (6 frames per second fps) imaging and 3D rotational road mapping). The higher device capabilities were important for better analysis of the complexity of the MCA aneurysms. For all cases, general anesthesia was administered (Figs. 1, 2, 3, 4, 5, 6, and 7).

Simple coiling technique was performed in case of relatively narrow neck aneurysm and balloon-assisted coiling for wide-neck aneurysms. A non-detachable balloon (e.g., Hyper form, ev3, Irvine, CA or scepterC $C^{\mathrm{mm}}$, Microvention, Tustin, CA, USA) was used for remodeling.

In stent-assisted coiling, Neuroform-atlas $3^{\text {mix }}$ stent (Boston Scientific, Natick, MA) or braided stents (e.g., Leo stents, Balt, Montmorency, France) were used as a single or in $\mathrm{Y}$ stent fashion in MCA bifurcation aneurysms.

Silk flow diverter stent (Balt, Montmorency, France) was used in two cases in this series.

Calculations were performed on the basis of established images as well as working planes. Administration of intravenous heparin (usually 50 units $/ \mathrm{kg}$ ) was performed before providing unruptured cases with the guide catheter and after secure deployment of at least one coil inside dome of aneurysm for ruptured cases. 


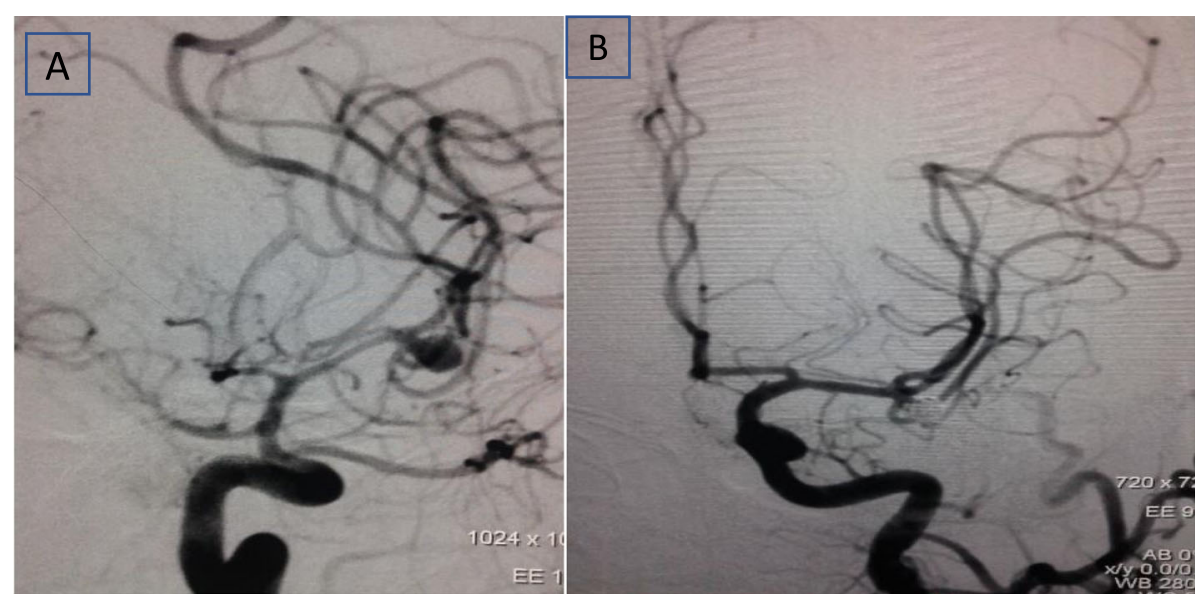

Fig. 1 Simple coiling of MCA bifurcation aneurysm, complete occlusion. No recanalization. A Before treatment, small-sized M1-2 bifurcation aneurysm. B After simple coiling. Complete occlusion, no recanalization

With regard to cases using stents, loading with and maintaining on aspirin $(100 \mathrm{mg})$ and ticagrelor $(90 \mathrm{mg}$, twice daily) were carried out to patients.

Upon using stents, patients were provided aspirin $100 \mathrm{mg}$ as well as ticagrelor $90 \mathrm{mg}$ (twice daily) until follow-up (the next 6 months), and then the ticagrelor is stopped, and the patient was treated for life on aspirin $100 \mathrm{mg}$.

\section{Statistical analysis}

Descriptive statistics were utilized for summarizing clinical as well as radiographic properties including aneurysm characteristics, demographics, and procedural approaches. Wilcoxon rank test, as appropriate, was utilized for continuous measures, and the chi-square test or Fisher's exact test, as appropriate, was utilized for categorical measures. All statistical examinations were
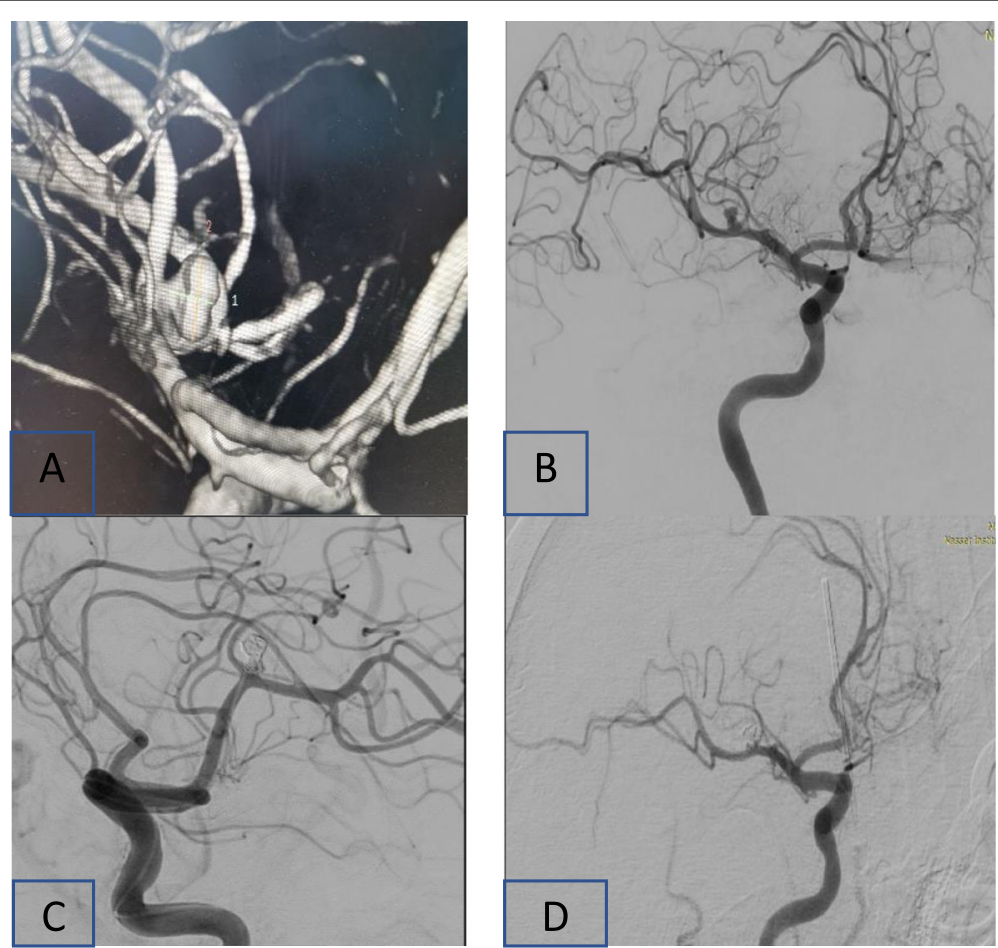

Fig. 2 MCA bifurcation aneurysm with complete total occlusion with simple coiling. A 3D reconstructed image of the aneurysm before treatment. B 2D, AP view of the aneurysm before treatment. C Lateral view, intra-procedural, with micro catheter coil deployment. D Angiographic follow-up showing complete total occlusion, no recanalization 


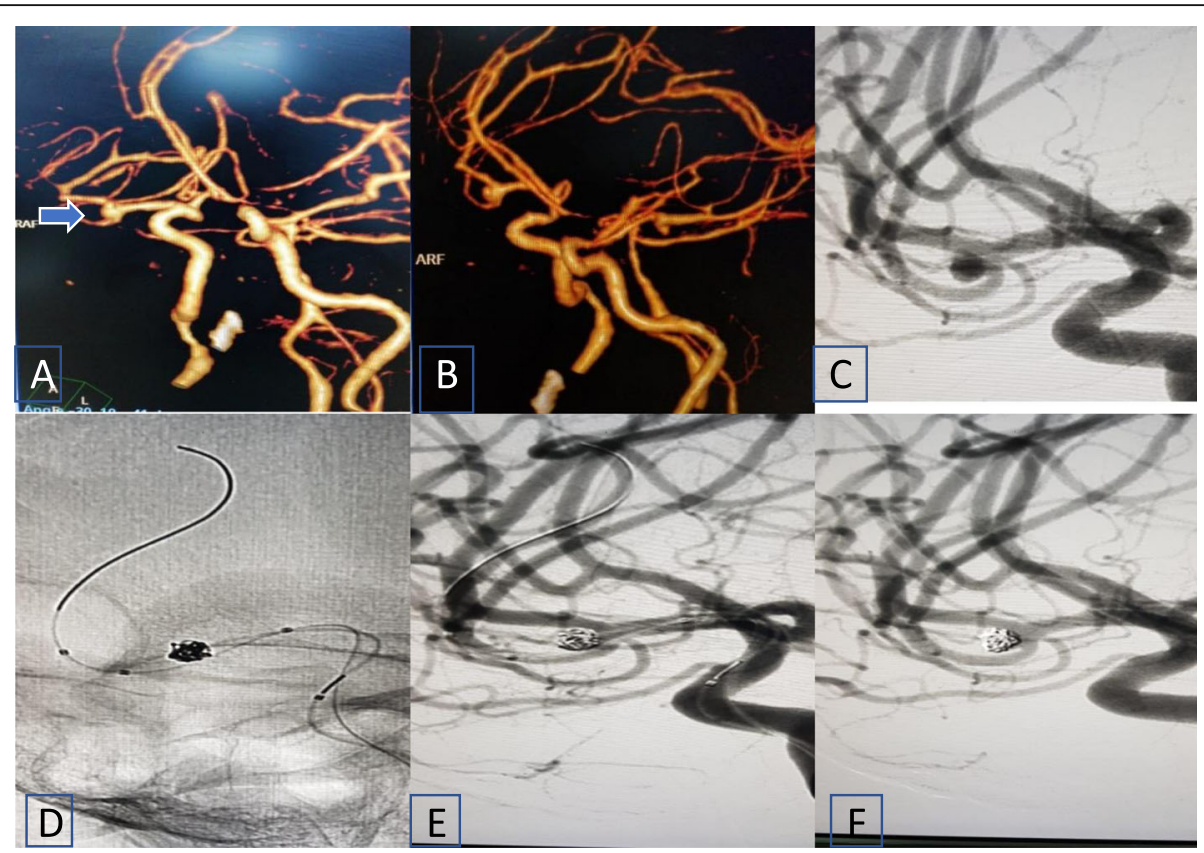

Fig. 3 Successful balloon-assisted coiling of M2 bifurcation aneurysm. A, B Reconstructed MDCT imaging of the aneurysm. C Diagnostic angiogram showing the wide neck of the aneurysm. $\mathbf{D}$ Intra-procedural with the balloon and the deployed coils within the sac. $\mathbf{E}$ After coil packing, intra-procedural. F Follow-up with stable dense packing, no recanalization
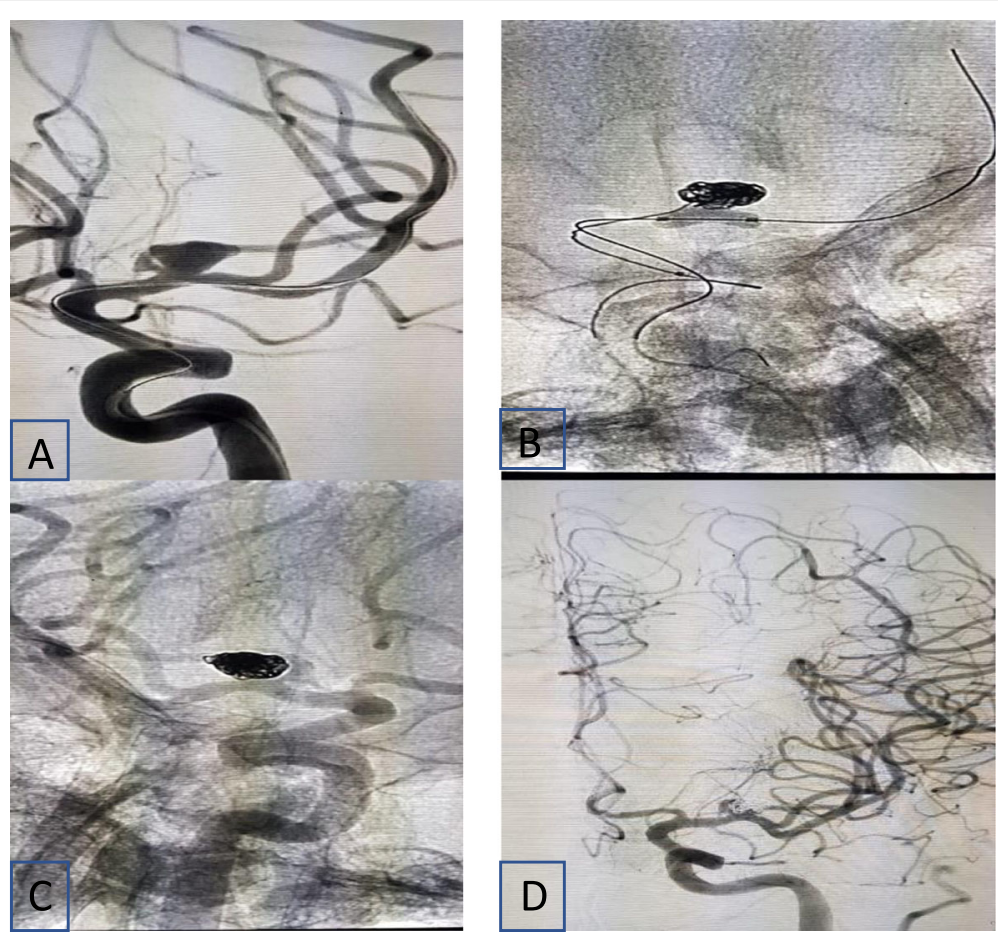

Fig. 4 Balloon-assisted coiling of wide neck M1 aneurysm with temporal branch arising from the neck of the aneurysm. A A-P view with the balloon. B Inflated balloon during coil deployment. C Control angiogram after coiling. D Follow-up showing stable occlusion, no recanalization 

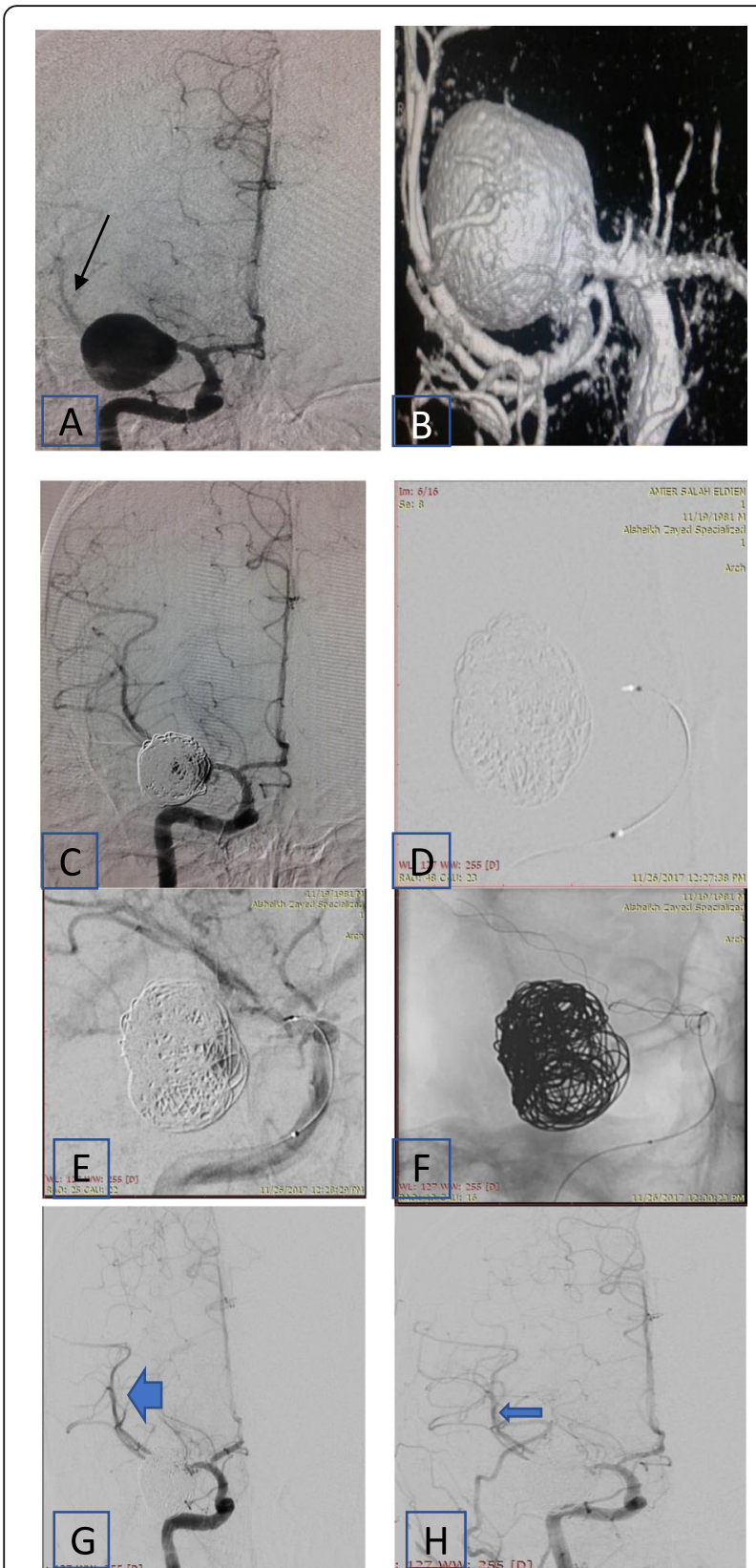

Fig. 5 Stent-assisted coiling of large M1-M2 aneurysm that requires further treatment after first follow-up; note the distal MCA branches filling after treatment. A A-P view showing large MCA, M1-M2 aneurysm; note the poor filling of the distal MCA branches (the black arrow). B 3D reconstruction image of the aneurysm. C After stent deployment, first follow-up showing contrast filling near the aneurysmal neck; subtraction image during advancement of the micro-catheter. E, $\mathbf{F}$ During microvascular passage through the mesh Struss. G, H Follow-up showing complete aneurysmal occlusion with noted good filling of the distal MCA branches (the blue arrows)

two-sided, and $p<0.05$ was regarded as statistically significant. All statistical analyses were conducted using SPSS version 25.

\section{Results}

\section{Patient demographics}

Thirty patients with MCA aneurysms were reviewed; all patients underwent successful endovascular treatment. The average age of the patients involved was $51.6 \pm 10.1$ years, ranging from 23 to 72 , with 10 (33.3\%) females and $20(66.7 \%)$ males.

\section{Aneurysm characteristics}

Of the treated patients, 24 patients $(80 \%)$ were having only MCA aneurysm and 6 (20\%) patients were having multiple aneurysms including MCA. Twenty-three (76.7\%) were ruptured and 7 (23.3\%) were unruptured. Twenty-four $(80 \%)$ aneurysms were small sized (2-6 $\mathrm{mm}), 4(13.3 \%)$ were medium sized $(6-12 \mathrm{~mm})$, and only 2 (6.7\%) were large ones (12-25 mm). Twelve (40\%) were narrow neck aneurysms and 18 (60\%) were wide neck. Twelve $(40 \%)$ were having a branch arising from the neck and $2(6.7 \%)$ were having a branch from the sac (Table 1).

\section{Treatment modality}

Of the treated aneurysms, 15 aneurysms (50\%) were treated with simple coiling, 13 aneurysms (43.3\%) required vascular remodeling with 5 (16.7\%) being treated using balloon-assisted coiling, 7 cases require stentassisted coiling, and 1 case (3.3\%) was done using double catheter technique. Two unruptured cases $(6.7 \%)$ of the sample were treated with flow diverter stents (Table 2).

\section{Initial angiographic results}

Of the treated aneurysms, 24 (80\%) achieved a complete or near-complete (Raymond 1 or 2) occlusion at first 6 months follow-up with 17 (56.7\%) complete occlusion at 1 year follow-up with only 4 (13.3\%) aneurysms required further treatment. Seven (23.3\%) patients did not show up at the 1 year follow-up, and $2(6.7 \%)$ patients died due to other causes not related to the procedure (Table 3 ).

\section{Relationship between the treatment modality and angiographic results}

Despite the numbers in each group, better angiographic result (with less recanalization) rates were noted with remodeling techniques and the flow diverter stents (Table 4).

\section{Complications and mortality}

Vasospasm was the most common complication found on 6 patients (20\%), and it was disease related, due to the subarachnoid hemorrhage, with no significant effect on the clinical outcomes of patients. Two patients $(6.7 \%)$ had intra-procedural complications: one was temporary and resolved post procedural after elevation of the patient blood pressure due to slowing down of the flow after deployment of flow diverter stent jailing an M2 

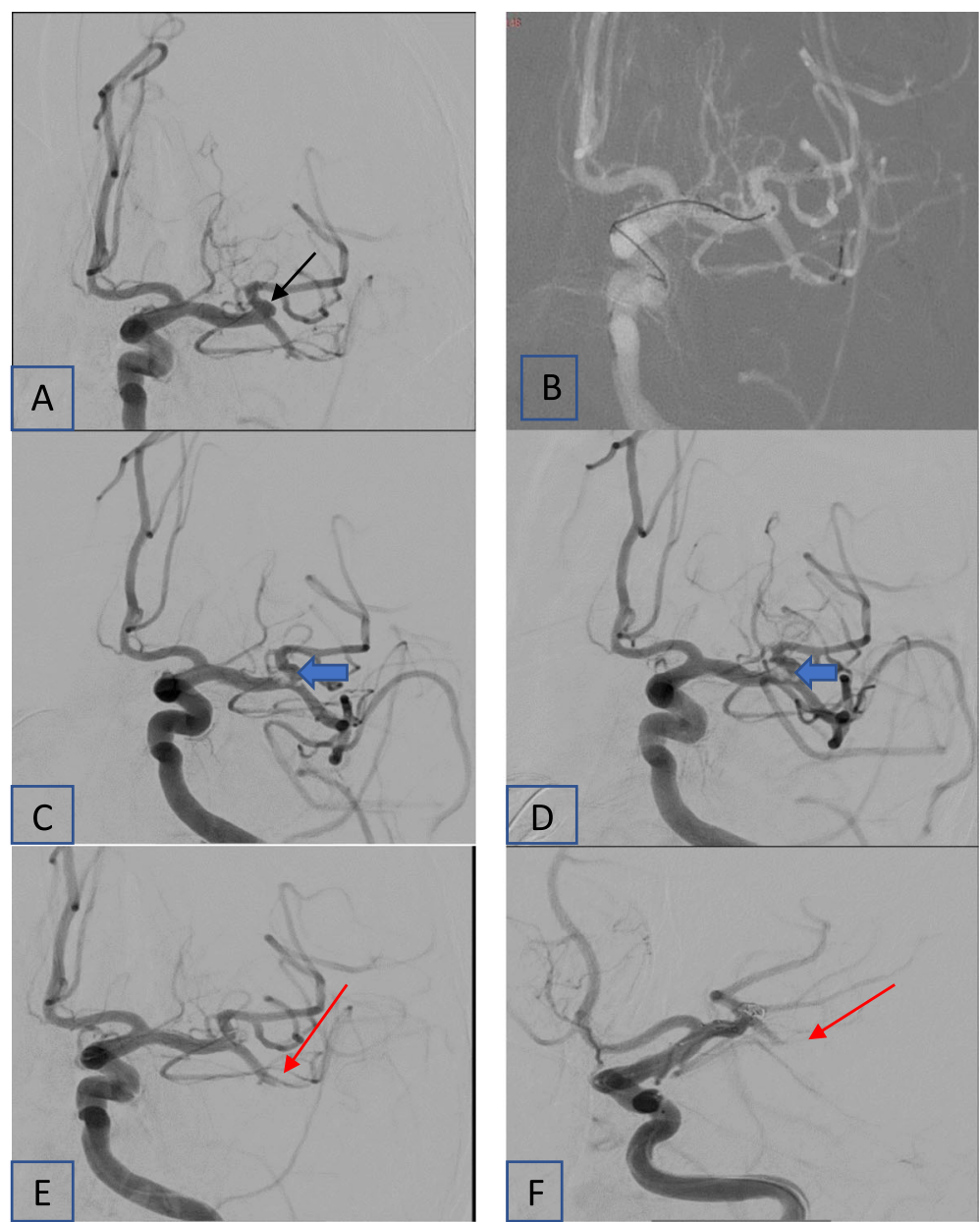

Fig. 6 Thromboembolic complication. Small M1-M2 bifurcation wide neck aneurysm, planned to be treated with T-stenting. A AP angiogram showing the small aneurysm (the black arrow). B During advancement of the micro-catheter. C Noted thrombus dislodgment, the filling defect at the $\mathrm{M} 1$ segment (the blue arrow). D Trial of mechanical thrombectomy ended by dislodgment of the thrombus into the inferior M2 branch (amputated branch, red arrow). Patient then developed severe chest infection at the ICU and died

branch, and the other case was due to embolic occlusion and a trial of mechanical thrombectomy was done; however, it resulted in permanent occlusion of a small M2 branch. This patient developed an ischemic insult on follow-up MDCT with neurological deficit; this patient was the only patient who died post procedural due to severe chest infection in the ICU. One case (3.3\%) had a coil migration which was early presented by facial tingling that was resolved on 1 -week post procedure. No complications were found in the other treated 20 cases (66.7\%) (Table 5).

\section{Clinical outcome}

Of the patient population, 28 (93.3\%) had a postoperative mRS of $0-2$ at 3 months (Table 6). One patient died (of the severe infection), and one did not show up at the time of the follow-up.

\section{Discussion}

\section{Radiological outcome}

The management of middle cerebral artery aneurysms (MCA) has been challenged and perplexed in the existence of changes in aneurysm practice. For a long time, such aneurysms have been undesirable for coiling on the basis of their trifurcated anatomy, dysmorphic shapes, broad necks, and branches, which can be angiographically undecipherable. In contrast, MCA aneurysms have long been desirable for clipping due to their accessibility, ease of manipulation following Sylvian fissure splitting, and their utility to other methods of treatment such as clip reconstruction, in addition to bypass upon failure of traditional clipping systems $[5,11]$.

MCA aneurysms EVT were inadequately represented in ISAT trial (303 aneurysms, 14.1\%, while in the majority of other aneurysm series, they represent one fourth 

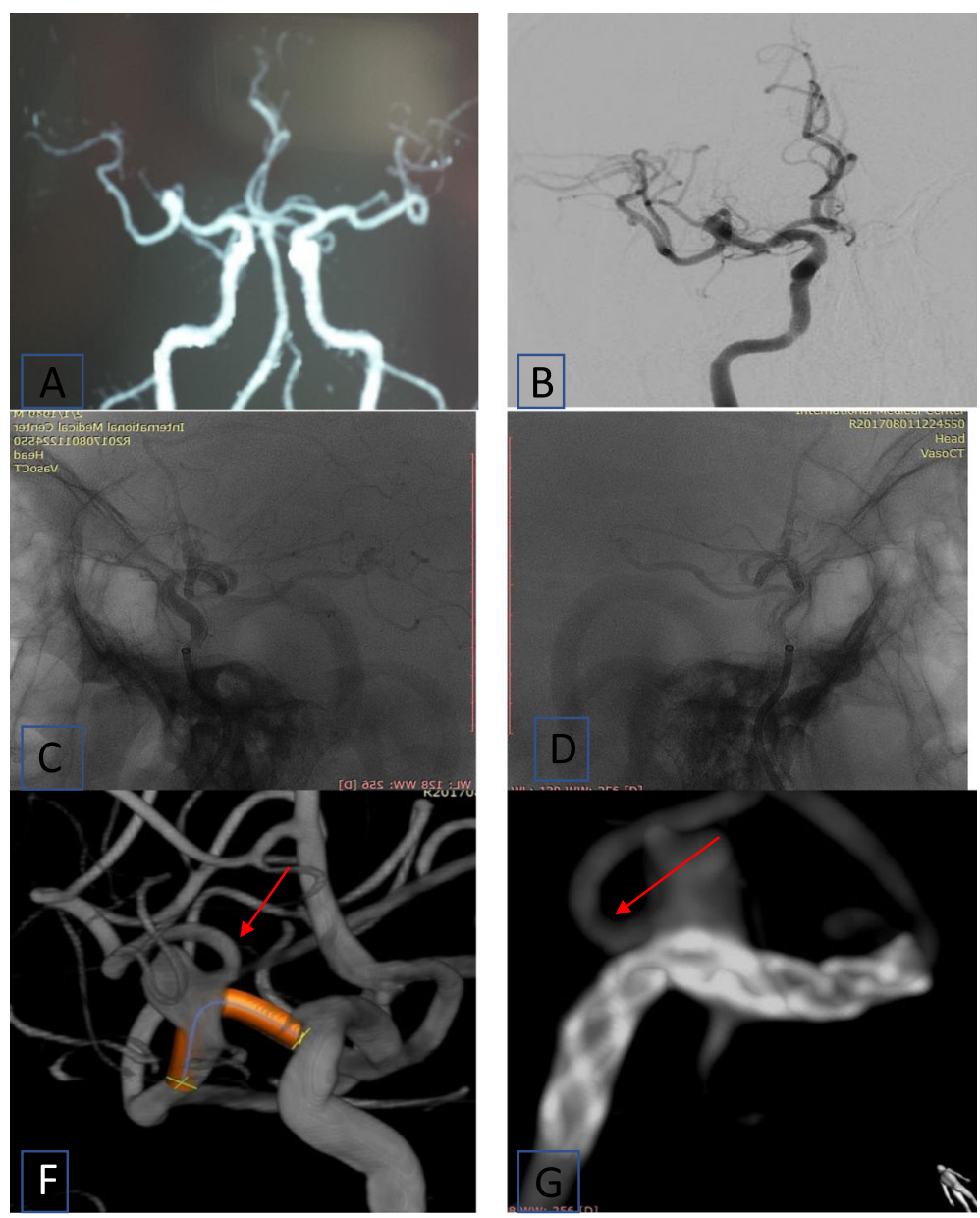

Fig. 7 Example of flow diverter stent in wide neck M1 aneurysm with a branch arising from the sac. Immediately after the procedure, the patient develops left hemiplegia which raises the suspicion of thromboembolic complication. DSA revealed patent stent with slowing down of the flow within the covered branch (red arrow), no stent thrombosis; this was corrected by elevation of the patient blood pressure. Complete occlusion of the aneurysm was achieved with no complications. A Reconstructed MDCT image showing M1 aneurysm with aneurysmal branch from the sac. B A-p view DSA, showing the aneurysm and the sac branch. C Just after deployment of the stent. D Slowing down of the flow in the aneurysmal branch. E Road mapping for the stent deployment. F Vaso-CT after stent deployment

Table 1 Aneurysm characteristics among the treated group

\begin{tabular}{|c|c|c|c|c|c|}
\hline \multirow[t]{2}{*}{ No of aneurysms } & \multicolumn{2}{|c|}{ MCA aneurysm } & \multicolumn{2}{|c|}{ Multiple aneurysms including MCA one } & \\
\hline & \multicolumn{2}{|l|}{$24(80 \%)$} & \multicolumn{2}{|l|}{$6(20 \%)$} & \\
\hline \multirow[t]{2}{*}{ Status of the aneurysm } & \multicolumn{2}{|l|}{ Unruptured } & \multicolumn{2}{|l|}{ Ruptured } & \\
\hline & \multicolumn{2}{|l|}{$7(23.3 \%)$} & \multicolumn{2}{|l|}{$23(76.7 \%)$} & \\
\hline \multirow[t]{2}{*}{ Size of the aneurysm } & \multicolumn{2}{|c|}{ Small aneurysms } & \multicolumn{2}{|c|}{ Medium sized aneurysms } & Large aneurysms \\
\hline & \multicolumn{2}{|l|}{$24(80 \%)$} & \multicolumn{2}{|l|}{$4(13.3 \%)$} & $2(6.7 \%)$ \\
\hline \multirow[t]{2}{*}{ Site of the aneurysm } & M1 segment & M1-M2 segment & M2 segment & M3 segment & Multiple segments \\
\hline & $12(40 \%)$ & $10(33.3 \%)$ & $6(20 \%)$ & $0(0 \%)$ & $2(6.7 \%)$ \\
\hline \multirow[t]{2}{*}{ Aneurysmal branch } & \multicolumn{2}{|c|}{ Branch from the neck } & \multicolumn{2}{|c|}{ Branch from the sac } & No branch \\
\hline & \multicolumn{2}{|l|}{$12(40 \%)$} & \multicolumn{2}{|l|}{$2(6.7 \%)$} & $16(53.3 \%)$ \\
\hline \multirow[t]{2}{*}{ Neck shape } & \multicolumn{2}{|l|}{ Narrow neck } & \multicolumn{2}{|l|}{ wide neck } & \\
\hline & \multicolumn{2}{|l|}{12 (40\%) } & \multicolumn{2}{|l|}{$18(60 \%)$} & \\
\hline
\end{tabular}


Table 2 Treatment modality regarding coiling, remodeling techniques

\begin{tabular}{llllll}
\hline Treatment modality & Simple coiling & Balloon-assisted coiling & Stent-assisted coiling & Flow diverter stent & Double catheter technique \\
\hline & $15(50 \%)$ & $5(16.7 \%)$ & $7(23.3 \%)$ & $2(6.7 \%)$ & $1(3.3 \%)$ \\
\hline
\end{tabular}

of all aneurysms), reflecting the deficiency of therapeutic equipoise between clipping as well as coiling, which is indispensable for the inclusion of ISAT [14].

The ISAT trial resulted in the widespread adoption of (coil first) policy; this extended till the release of the results of the (BRAT trial) in 2012 that demonstrated a significant absolute risk reduction of $10.5 \%$ in comparison to clipping at 1-year follow-up [15].

Owing to the increased number of patients treated with endovascular route, there have been increasing interests exploring the safety and feasibility of coiling as an alternative option in MCA management [1].

This work reviewed 30 cases with MCA aneurysms, which were subjected to endovascular procedure from July 2017 to July 2018. The feasibility of successfully employed endovascular treatment was $100 \%$ in all cases. At 6 months follow-up, achieving occlusion (complete or near-complete) in 24 cases (80\%) was accomplished. At a long follow-up of 1 year, only 4 (26.7\%) cases of the simple coiling group required further treatment; this may be explained by the fact that MCA aneurysms have higher rates of recurrence being in direct continuation with the carotid arteries and having a complex morphology $[16,17]$. Other treated aneurysms with remodeling techniques except one case were found to be stable or improved in the Raymond occlusion classification; this may be explained by in balloon-assisted coiling; the balloon allows more packing density of the aneurysm [18], and the stents allow the add-on value of better endothelialization of the parent arteries [19]. Such results are identical to other preceding reported series [2-4, 20, 21]

Endovascular treatment of MCA aneurysms is somewhat underrepresented in published reports of literature. In general, between 2005 and 2010, evaluation of 795 MCA aneurysms was recorded in six reported series, describing initial rates regarding $46.1-77.2 \%$ of complete occlusion, $19.5-50 \%$ of near-complete occlusion, and $2.6-3.4 \%$ of incomplete occlusion [2-4, 6, 7, 22].

The range of overall recurrence rates was between 8 and $27.2 \%$ [3, 4, 9, 23]. In 2011, evaluation of 1076 aneurysms by meta-analysis derived from 12 published series resulted in rates for complete or near-complete occlusion as of $82.4 \%$, incomplete occlusion as of $12.7 \%$, and failed treatment as of $4.8 \%$ [8]. The recanalization with required treatment reached $9.6 \%$, while minor recanalization without necessary treatment reached 9.3\% [10].

In the recent study, published 2014 by Mounayer et al. [24], they observed $83.2 \%$ of total occlusion, and they had a recurrence rates of $15.6 \%$ with the higher rates of recanalization also found in the simple coiling group; this is comparable to the results found in our series [24].

Another recent series reported by Kadkhodayan et al. in 2014 including 292 patients and $346 \mathrm{MCA}$ aneurysms demonstrated an intraoperative thromboembolic event rate of $13.6 \%$, overall morbidity rate of $2.9 \%$ at 30-day follow-up, and complete or nearcomplete occlusion rate of $91.8 \%$, with an average of 2 years of follow-up [21].

Therefore, our findings of $80 \%$ short-term (at 6 months) complete or near-complete occlusion are similar to the above results, but we have a higher percentage of recanalization $16.7 \%$ than the above results; this may be attributed to the lower number of the sample.

Published report stated that recurrence with a high rate could be attributed to a larger size of aneurysm, ruptured aneurysms, and larger neck in addition to incomplete initial occlusion $[3,24]$. In our series, we had lower rates of recurrence with a better angiographic follow-up for those aneurysms due to the use of remodeling techniques, which allows better stable occlusion with a high packing density, even with aneurysms, featuring a branch vessel (which arises either from the sac or the fundus). We had a stable occlusion with minor or no complications, achieving a very identical rate to the overall rate of $90 \%$. In contrast, at the longest follow-up at 1 year, a stable-to-improved Raymond score was found in (56.7\%) due to high patient attrition, whereas 7 patients (23.3\%) did not appear for follow-up.

It was found that the use of stent alone appeared to improve the follow-up outcome, with all cases (100\%), leading to a stable-to-enhanced Raymond rating, but this was not statistically significant because of low number of cases.

Table 3 Angiographic follow-up

\begin{tabular}{lllll}
\hline Follow-up & & & & \\
\hline & No recanalization & Recanalization & Patient did not show up & Patient died \\
\hline $\mathbf{6}$ months & $24(80 \%)$ & $5(16.7 \%)$ & $0(0 \%)$ & $1(3.3 \%)$ \\
$\mathbf{1}$ year & $17(56.7 \%)$ & $4(13.3 \%)$ & $7(23.3 \%)$ & $2(6.7 \%)$ \\
\hline
\end{tabular}


Table 4 Relationship between the treatment modality and angiographic follow-up

\begin{tabular}{|c|c|c|c|}
\hline & & \multicolumn{2}{|l|}{ Follow-up } \\
\hline & & 6 months & 1 year \\
\hline Simple coiling & $\begin{array}{l}\text { No recanalization } \\
\text { Recanalization } \\
\text { Patient did not show up } \\
\text { Patient died }\end{array}$ & $\begin{array}{l}11(73.3 \%) \\
4(26.7 \%) \\
0(0 \%) \\
0(0 \%)\end{array}$ & $\begin{array}{l}7(46.7 \%) \\
4(26.7 \%) \\
4(26.7 \%) \\
0(0 \%)\end{array}$ \\
\hline Balloon-assisted coiling & $\begin{array}{l}\text { No recanalization } \\
\text { Recanalized } \\
\text { Patient did not show up } \\
\text { Patient dies }\end{array}$ & $\begin{array}{l}5(100 \%) \\
0(0 \%) \\
0(0 \%) \\
0(0 \%)\end{array}$ & $\begin{array}{l}4(80 \%) \\
0(0 \%) \\
1(20 \%) \\
0(0 \%)\end{array}$ \\
\hline Stent-assisted coiling & $\begin{array}{l}\text { No recanalization } \\
\text { Recanalized } \\
\text { Patient did not show up } \\
\text { Patient dies }\end{array}$ & $\begin{array}{l}5(71.4 \%) \\
1(14.3 \%) \\
0(0 \%) \\
1(14.3 \%)\end{array}$ & $\begin{array}{l}4(57.1 \%) \\
0(0 \%) \\
1(14.3 \%) \\
2(28.6 \%)\end{array}$ \\
\hline Flow diverter stent & $\begin{array}{l}\text { No recanalization } \\
\text { Recanalized } \\
\text { Patient did not show up } \\
\text { Patient dies }\end{array}$ & $\begin{array}{l}2(100 \%) \\
0(0 \%) \\
0(0 \%) \\
0(0 \%)\end{array}$ & $\begin{array}{l}1(50 \%) \\
0(0 \%) \\
1(50 \%) \\
0(0 \%)\end{array}$ \\
\hline Double catheter technique & $\begin{array}{l}\text { No recanalization } \\
\text { Recanalized } \\
\text { Patient did not show up } \\
\text { Patient dies }\end{array}$ & $\begin{array}{l}1(100 \%) \\
0(0 \%) \\
0(0 \%) \\
0(0 \%)\end{array}$ & $\begin{array}{l}1(100 \%) \\
0(0 \%) \\
0(0 \%) \\
0(0 \%)\end{array}$ \\
\hline
\end{tabular}

Our results are controversial to that published by Vendrell et al. in 2009, where they found a higher rate of recurrence in the long term with the balloon use. Such findings are most probably because the use of balloons or stents was carried out when cases were more challenging with only (complex anatomy), and thus, bias is created [9].

Flow diversion has recently been utilized as a substitute method for complex wide-neck MCA aneurysms with the incorporation of more than one side branch or in treated cases of previous endovascular or failed surgery $[25,26]$. Nevertheless, their function in the MCA aneurysms still controversial due to certain factors: (1) occlusion rate of aneurysm, (2) treatment-related complications as well as clinical outcome, and (3) the fate of the MCA side branch covered with the device. A metaanalysis published in 2017 found that occlusion (complete/near-complete) overall rate was around $80 \%$. Following treatment, the rate of rupture was low $(0.4 \%$ per aneurysm/year), manifesting the successful security of aneurysms following flow diversion. The majority of lesions were small and positioned at the major bifurcation point (M1-M2). The overall rate of complication $(20 \%)$ is somewhat essential, leading to perpetual neurological deficiencies in patients (10\%), while treatment-correlated mortality represents 2\%. More interestingly, the majority of undesirable outcomes were correlated to complications that originated from ischemia or thromboembolism. This research work also stated an outstanding incidence of occlusion $(10 \%)$ and reduced flow (25\%) of jailed MCA branches, affecting patients $(5 \%)$ with neurological symptoms. Such results are significant and demonstrated that although treatment with flow diversion is a highly efficient route, careful selection of MCA aneurysms subjected to flow diversion is of paramount significance because of the non-negligible rates of treatment-related morbidity [27].

\section{Complications and morbidity}

Vasospasm was the most encountered complication in our series, and it was related to the disease pathophysiology (the SAH), not the procedure. We had a low rate of thromboembolic complications, 2 cases (6.7\%), with one case finally had complete occlusion of one of the M2 branches, while the other case had a slowdown of the flow in aneurysmal branch after deployment of a flow diverter stent, which was reversed by increasing the patient blood pressure, and this is not matching with

Table 5 Complications and mortality

\begin{tabular}{lllll}
\hline Complications and mortality & & & \\
\hline Complications & Flow related including thromboembolic & Coil migration & Vasospasm & No complications \\
Mortality & $2(6.7 \%)$ & $1(3.3 \%)$ & $6(20 \%)$ & $20(66.7 \%)$ \\
& Yes & No & & \\
& $1(3.3 \%)$ & $29(96.7 \%)$ & & \\
\hline
\end{tabular}


Table 6 Clinical outcome assessed at 3 months using the modified Rankin scale

\begin{tabular}{lllllll}
\hline MRS, 3 months & & & & \\
\hline MRS & Dead & Moderate to severe disability & Slight disability & No significant disability & No disability & Patient did not show up \\
\hline & $1(3.3 \%)$ & $0(0 \%)$ & $0(0 \%)$ & $0(0 \%)$ & $28(93.3 \%)$ & $28(93.3 \%)$
\end{tabular}

other studies $[2-4,7-9,23]$. The rate of TE events in these studies was in the range between 8.5 and $19.6 \%$. Furthermore, the encountered two mortality cases in our series were not related to the procedure; one was related to a severe chest infection in the neurology ICU, and the other was related to other cardiac causes after 1 year of treatment. A meta-analysis conducted in 2011 identified the overall morbidity/mortality for unruptured as $5.1 \%$, for ruptured aneurysms as $6.0 \%$, and particularly morbidity because of TE complication as 3.2\% [10].

The variation in our findings probably shows over the last decade the improved technology and advancement of the devices including compliant balloons, intermediate, and micro catheters.

\section{Limitations}

This study was prospective within a limited time, which was reflected in the low number of samples for adjusting the time of the follow-ups as presented. The loss of several patients was caused by insurance or geographic causes.

No comparative surgical arm was used in this study, and we depended on the previously published studies in discussing the surgical outcome.

\section{Conclusions}

In this study, we stress the fact that MCA aneurysms even the complex ones can safely and effectively be treated by endovascular means particularly after improvement of the technology, the evolution of new devices, and higher operator experience with a very low mortality and morbidity incidence.

\section{Abbreviations}

MCA: Middle cerebral artery; EVT: Endovascular treatment; SAH: Subarachnoid hemorrhage; mRS: Modified Rankin Scale; TE: Thromboembolic;

ISAT: International subarachnoid trial; MDCT: Multidetector CT

\section{Acknowledgements}

None

\section{Authors' contributions}

All authors had actively participated in this paper and agreed both to be personally accountable for the author's own contributions and ensuring that questions related to the accuracy or integrity of any part of the work, even ones in which the author was not personally involved, are appropriately investigated, resolved, and the resolution documented in the literature. All authors have read and approved the manuscript. The idea and design of work was done by F. H (the principal author). Dr. A. I (the corresponding author) and prof. F. H contributed to the data collection and performing of the endovascular procedures for the participants. Dr. A. I collected the data of the patients and did the excel sheets and follow-up of the patients. Prof.
M.E (the first author) contributed to the conception with a major role in the manuscript writing, interpretation of data, and revision of work. Professor M. I and professor $\mathrm{O}$. W shared with the interpretation of data and the revision of the manuscript. Prof. M. E (first author): contribution to the conception, interpretation of data, and revision. Dr. A. I (corresponding and second author): acquisition, analysis, drafted the manuscript, and submission. Prof. M. I: interpretation of data and revision. Prof. O.W: interpretation of data and revision. Prof. F. H (principle author): design of the work, acquisition, analysis, and revision

\section{Funding}

None

Availability of data and materials

Data and materials are available.

\section{Declarations}

Ethics approval and consent to participate

At that time when the study started, the ethical committee at Faculty of Medicine, Minia University, was not fully activated. Therefore, we got the permission from the relevant department and then approval from the faculty council (faculty of medicine council, approval date: 19 November, 2017). Based on the journal guidelines, we submitted a request to the ethical committee, and the study was approved by the ethical committee, Minia Faculty of Medicine, Minia, Egypt (attached ethical committee letter). Ethical committee chairman: Prof. Manal Ismail Abd-El Ghany, manal. abdelghany@mu.edu.eg

All patients or their first-degree relatives (if not fully conscious) signed a written approval for participation.

\section{Consent for publication}

All patients included in this research gave written informed consent to publish the data contained within this study. If the patients were less than 16 years old, deceased, or unconscious when consent for publication was requested, written informed consent for the publication of this data was given by their parents or legal guardians.

\section{Competing interests}

None of the authors have any conflict of interest to disclose.

\section{Author details}

${ }^{1}$ Radiology Department, Faculty of Medicine, Minia University, Minia, Egypt. ${ }^{2}$ Radiology Department, Kasr El Ainy School of Medicine, Kasr A Ainy St, Cairo 11562, Egypt.

Received: 28 September 2020 Accepted: 16 June 2021

Published online: 28 June 2021

References

1. Yang W, Huang J (2015) Treatment of middle cerebral artery (MCA) aneurysms: a review of the literature. Chin Neurosurg J 1(1):1-7. https://doi. org/10.1186/s41016-015-0001-8

2. Doerfler A, Wanke I, Goericke $S$, Wiedemayer H, Engelhorn T, Gizewski $E_{\text {, }}$ Stolke D, Forsting M (2006) Endovascular treatment of middle cerebral artery aneurysms with electrolytically detachable coils. Am J Neuroradiol 27(3):513-520

3. Bracard S, Abdel-Kerim A, Thuillier L, Klein O, Anxionnat R, Finitsis S, Lebedinsky A, de Freitas CM, Pinheiro N, de Andrade GC, Picard L (2010) Endovascular coil occlusion of 152 middle cerebral artery aneurysms: initial and midterm angiographic and clinical results. J Neurosurg 112(4):703-708. https://doi.org/10.3171/2009.6.JNS09483 
4. lijima A, Piotin M, Mounayer C, Spelle L, Weill A, Moret J (2005) Endovascular treatment with coils of 149 middle cerebral artery berry aneurysms. Radiology. 237(2):611-619. https://doi.org/10.1148/radiol.2372 041015

5. Rodríguez-Hernández A, Sughrue ME, Akhavan S, Habdank-Kolaczkowski J, Lawton MT (2013) Current management of middle cerebral artery aneurysms: surgical results with a "clip first" policy. Neurosurgery. 72(3):415427. https://doi.org/10.1227/NEU.0b013e3182804aa2

6. Smith TR, Cote DJ, Dasenbrock HH, Hamade YJ, Zammar SG, El Tecle NE et al (2015) Comparison of the efficacy and safety of endovascular coiling versus microsurgical clipping for unruptured middle cerebral artery aneurysms: a systematic review and meta-analysis. World Neurosurg 84(4): 942-953. https://doi.org/10.1016/j.wneu.2015.05.073

7. Guglielmi G, Viñuela F, Duckwiler G, Jahan R, Cotroneo E, Gigli R (2008) Endovascular treatment of middle cerebral artery aneurysms: overall perioperative results. Apropos of 113 Cases. Interv Neuroradiol 14(3):241245. https://doi.org/10.1177/159101990801400303

8. Suzuki S, Tateshima S, Jahan R, Duckwiler GR, Murayama Y, Gonzalez NR, Viñuela F (2009) Endovascular treatment of middle cerebral artery aneurysms with detachable coils: angiographic and clinical outcomes in 115 consecutive patients. Neurosurgery. 64(5):876-889. https://doi.org/10.1227/ 01.NEU.0000343534.05655.37

9. Vendrell J-F, Menjot N, Costalat V, Hoa D, Moritz J, Brunel H, Bonafe A (2009) Endovascular treatment of 174 middle cerebral artery aneurysms: clinical outcome and radiologic results at long-term follow-up. Radiology. 253(1): 191-198. https://doi.org/10.1148/radiol.2531082092

10. Brinjikji W, Lanzino G, Cloft HJ, Rabinstein A, Kallmes DF (2011) Endovascular treatment of middle cerebral artery aneurysms: a systematic review and single-center series. Neurosurgery. 68(2):397-402. https://doi.org/10.1227/ NEU.0b013e318201d7f4

11. Lawton MT, Quinones-Hinojosa A, Sanai N, Malek JY, Dowd CF (2003) Combined microsurgical and endovascular management of complex intracranial aneurysms. Neurosurgery. 52(2):263-275. https://doi.org/10.1227/ 01.NEU.0000043642.46308.D1

12. Lawton MT (2011) Selecting therapy for complex aneurysms. World Neurosurg 75(3-4):408

13. Rodríguez-Hernández A, Lawton MT (2011) Flash fluorescence with indocyanine green videoangiography to identify the recipient artery for bypass with distal middle cerebral artery aneurysms: operative technique. Operative Neurosurg 70(suppl_2):ons209-ons20

14. Sanai N, Zador Z, Lawton MT (2009) Bypass surgery for complex brain aneurysms: an assessment of intracranial-intracranial bypass. Neurosurgery. 65(4):670-683. https://doi.org/10.1227/01.NEU.0000348557.11968.F1

15. McDougall CG, Spetzler RF, Zabramski JM, Partovi S, Hills NK, Nakaji P et al (2012) The barrow ruptured aneurysm trial. J Neurosurg 116(1):135-144. https://doi.org/10.3171/2011.8.JNS101767

16. Raymond J, Guilbert F, Weill A, Georganos SA, Juravsky L, Lambert A et al (2003) Long-term angiographic recurrences after selective endovascular treatment of aneurysms with detachable coils. Stroke. 34(6):1398-1403. https://doi.org/10.1161/01.STR.0000073841.88563.E9

17. Investigators ${ }^{*} \mathrm{C}(2006)$ Rates of delayed rebleeding from intracranial aneurysms are low after surgical and endovascular treatment. Stroke. 37(6): 1437-1442. https://doi.org/10.1161/01.STR.0000221331.01830.ce

18. Leng B, Zheng Y, Ren J, Xu Q, Tian Y, Xu F (2014) Endovascular treatment of intracranial aneurysms with detachable coils: correlation between aneurysm volume, packing, and angiographic recurrence. J Neurointervent Surg 6(8): 595-599. https://doi.org/10.1136/neurintsurg-2013-010920

19. Vendrell J-F, Costalat V, Brunel H, Riquelme C, Bonafe A (2011) Stent-assisted coiling of complex middle cerebral artery aneurysms: initial and midterm results. Am J Neuroradiol 32(2):259-263. https://doi.org/10.3174/ajnr.A2272

20. Kim K-H, Cha K-C, Kim J-S, Hong S-C (2013) Endovascular coiling of middle cerebral artery aneurysms as an alternative to surgical clipping. J Clin Neurosci 20(4):520-522. https://doi.org/10.1016/j.jocn.2012.02.054

21. Kadkhodayan Y, Delgado Almandoz JE, Fease JL, Scholz JM, Blem AM, Tran K, Crandall BM, Tubman DE (2015) Endovascular treatment of 346 middle cerebral artery aneurysms: results of a 16-year single-center experience. Neurosurgery. 76(1):54-61. https://doi.org/10.1227/NEU.0000000000000562

22. Henkes H, Fischer S, Weber W, Miloslavski E, Felber S, Brew S, Kuehne D (2004) Endovascular coil occlusion of 1811 intracranial aneurysms: early angiographic and clinical results. Neurosurgery. 54(2):268-285. https://doi. org/10.1227/01.NEU.0000103221.16671.F0
23. Quadros R, Gallas S, Noudel R, Rousseaux P, Pierot L (2007) Endovascular treatment of middle cerebral artery aneurysms as first option: a single center experience of 92 aneurysms. Am J Neuroradiol 28(8):1567-1572. https://doi.org/10.3174/ajnr.A0595

24. Gory B, Rouchaud A, Saleme S, Dalmay F, Riva R, Caire F, Mounayer C (2014) Endovascular treatment of middle cerebral artery aneurysms for 120 nonselected patients: a prospective cohort study. Am J Neuroradiol 35(4): 715-720. https://doi.org/10.3174/ajnr.A3781

25. Bhogal P, AlMatter M, Bäzner H, Ganslandt O, Henkes H, Aguilar PM (2017) Flow diversion for the treatment of MCA bifurcation aneurysms-a single centre experience. Front Neurol 8:20

26. Bhogal P, Martinez R, Gansladt O, Bäzner H, Henkes H, Aguilar M (2018) Management of Unruptured Saccular Aneurysms of the M1 segment with flow diversion. Clin Neuroradiol 28(2):209-216. https://doi.org/10.1007/ s00062-016-0553-9

27. Cagnazzo F, Mantilla D, Lefevre P-H, Dargazanli C, Gascou G, Costalat V (2017) Treatment of middle cerebral artery aneurysms with flow-diverter stents: a systematic review and meta-analysis. Am J Neuroradiol 38(12): 2289-2294. https://doi.org/10.3174/ajnr.A5388

\section{Publisher's Note}

Springer Nature remains neutral with regard to jurisdictional claims in published maps and institutional affiliations.

\section{Submit your manuscript to a SpringerOpen ${ }^{\circ}$ journal and benefit from:}

- Convenient online submission

- Rigorous peer review

- Open access: articles freely available online

High visibility within the field

- Retaining the copyright to your article

Submit your next manuscript at $>$ springeropen.com 